\title{
Clarithromycin-loaded Chitosan Nanoparticles: Preparation, Characterisation and Antibacterial Activity on Streptococcus pneumonia
}

\author{
H. M. ASHVINI*, A. BALLAAND S. K. MUTTA \\ Department of Pharmaceutics, Acharya \& B M Reddy college of Pharmacy, Bengaluru-560 107, India
}

Ashvini et al.: Preparation and Characterization of Clarithromycin Nanoparticles

\begin{abstract}
Clarithromycin-loaded chitosan nanoparticles were prepared and evaluated for antibacterial activity against Streptococcus pneumonia. Infrared and differential scanning calorimetry studies ruled out any possibility of interaction between clarithromycin and excipients used. Formulations were prepared using ionic gelation method. From the results, it was found that percent entrapment efficiency of formulations ranged between $12.1 \pm 0.67$ to $59.45 \pm 4.05 \%$, particle size between $155.31 \pm 23.36$ to $360.05 \pm 26.06 \mathrm{~nm}$ with narrow size distributions except F1, F2, F3 and zeta potential between $+11.96 \pm 0.5$ to $+26.83 \pm 0.4 \mathrm{mV}$. The in vitro drug release was found to be good with $75.1 \pm 1.01,72.4 \pm 2.14,68.1 \pm 1.96$ and $65 \pm 1.52 \%$ release for F4, F5, F6 and F7, respectively. From the results of kinetic studies, formulations were found to be more linear towards Higuchi model with $R^{2}$ value ranging from 0.843 to 0.964 indicating that drug release mechanism by diffusion and $\mathbf{n}$ value of Korsemeyer-Peppas plot was found to be less 0.5 indicating Fickian diffusion. In vitro antibacterial activity was performed against Streptococcus pneumonia. Their minimum inhibition concentration values of F4 and F5 was 1/4th and 1/2nd of minimum inhibition concentration of clarithromycin. Results of in vitro antibacterial studies showed that, the clarithromycin nanoparticles have more antibacterial property than intact drug.
\end{abstract}

Key words: Clarithromycin, chitosan nanoparticles, antibacterial activity

Chitosan (CS) is a linear copolymer of $\beta$-(1-4)linked 2-acetamido-2-deoxy-beta-D-glucopyranose and 2-amino-2-deoxy-3-D-glucopyranose, obtained by deacetylation of its parent polymer chitin, the second most abundant in nature after cellulose ${ }^{[1]}$. The bactericidal action of CS is well known and is due to an electrostatic interaction between $\mathrm{NH}_{3}{ }^{+}$groups of $\mathrm{CS}$ and phosphoryl groups of phospholipid components and lipopolysaccharides of bacterial cell membranes. This leads to an increase in the permeability formation of pores and finally disrupts the bacterial cell wall ${ }^{[2-4]}$.

Bacterial infectious diseases ranging from cutaneous infection to deep-seated life-threatening infections such as pneumonia, endocarditis, septicaemia, osteomyelitis, and other metastatic complications ${ }^{[5-7]}$. Antibiotic are the usual treatment for bacterial infection $^{[8]}$. Bacterial infectious disease is still responsible for considerable global mortality despite antibiotic treatment ${ }^{[9-11]}$. The major challenges faced by localized treatment of respiratory tract infections are the rapid absorption and clearance of antibiotics from

*Address for correspondence E-mail: ashviniherimatha@gmail.com

March-April 2019 the lungs. A critical obstacle and challenge for bacterial infectious therapy concerns the limited availability of effective biocompatible delivery system for most hydrophobic therapeutic and antimicrobial resistance. Intracellular infections and acquired resistance of infectious microbes are also key challenges ${ }^{[12]}$.

The clinical treatment failure of bacterial infectious disease is associated with low bioavailability of antibiotics, side effects of antibiotics, tissue and cellular barriers, biofilm-related infection and the emergence of resistant bacteria. Polymeric nanoparticles (NPs) and microparticles have been shown to have the potential to provide controlled drug delivery to the lungs, with sustained release of drugs so as to prolong drug

This is an open access article distributed under the terms of the Creative Commons Attribution-NonCommercial-ShareAlike 3.0 License, which allows others to remix, tweak, and build upon the work non-commercially, as long as the author is credited and the new creations are licensed under the identical terms

Accepted 11 February 2019

Revised 18 September 2018

Received 21 February 2018

Indian J Pharm Sci 2019;81(2):302-308 
action, reduce side effects, and to improve the patient compliance ${ }^{[13]}$.

Nanotechnology in medicine is already largely considered and explored in many medical areas, especially in drug delivery. NPs encapsulating antibiotics have shown great probability in substituting the administration of antibiotics in their free form. Polymeric NPs deliver antibiotics into very dense tissue and inaccessible cells. In case of NPs, the major fraction of the API can be released due to the smaller particle size and with this, shorter the diffusional distance between inner matrix and the environment ${ }^{[14]}$. Designing a NP formulation for antibacterial drug may prolong therapeutic by decrease the frequency of dosing and also improve the efficacy of drug and patient compliance. Literature indicated that NP formulations of antibiotics have better antibacterial effect than conventional formulation.

Clarithromycin (CLM) is a broad spectrum antibiotic $^{[15]}$, which has been widely used to treat respiratory tract infections caused by Pseudomonas aeruginosa, Chlamydophila pneumoniae, Klebsiella pneumonia, Mycoplasma pneumonia, Streptococcus pneumonia and Haemophilus influenza ${ }^{[16]}$. CLM is practically insoluble in water and its poor solubility is $\mathrm{pH}$-dependent ${ }^{[17]}$. Acid stability of CLM makes it suitable for oral administration. Despite CLM being absorbed from GI tract, systemic bioavailability of CLM is relatively poor $(55 \%)^{[18]}$. CLM exerts its antibacterial action by binding to the 50 s ribosomal subunit of susceptible organisms and by inhibiting protein synthesis through translocation of aminoacyl transfer-RNA ${ }^{[19]}$.

Polymers used for NP construction are either natural or synthetic. Natural polymers include albumin, collagen, gelatin, CS, haemoglobin and alginate. Among water-soluble polymers available, CS is one of the most extensively studied ${ }^{[20]}$. The 5 key advantages that polymeric drug delivery products can offer are; localized and sustained delivery of drug, stabilization of the drug, release rate, which is less dependent on the drug properties and steady release rate with time.

In the present research work, formation of antibiotic NPs seems to be a good choice for treatment of respiratory tract infections. Using these NPs, the dose and dosing frequency of CLM and side effects could be minimized, patient's compliance improved by direct delivering of drug into lungs.

\section{MATERIALS AND METHODS}

CLM was obtained from Calyx Pharmaceuticals. CS was purchased from SigmaAldrich ( $85 \%$ deacetylation). Sodium tripolyphosphate was purchased from Yarrow Chem Pvt., Ltd., Mumbai. High performance liquid chromatography (HPLC) grade water, acetonitrile and methanol were purchase from S. D. Fine-Chem, Mumbai, India. Potassium dihydrogen phosphate was purchased from Finar Reagents and o-phosphoric acid was obtained from Merck Chemicals. All other chemicals used were of analytical grade or HPLC grade.

\section{Preparation of CLM-loaded CS NPs:}

CLM-loaded CS NPs were prepared by ionic gelation method $^{[21-23]}$. CS was dissolved in an aqueous solution of acetic acid at concentrations, $0.1,0.25$ and $0.5 \%$ ) under magnetic stirring at room temperature. CLM was dissolved in CS solution, to get concentration of $1 \mathrm{mg} / \mathrm{ml}$. Triphenyl phosphate (TPP) aqueous solution $(0.25 \%)$ was added drop-wise using a syringe and needle (Table 1). $\mathrm{pH}$ of the CS solution was maintained at 4-4.5. Stirring was continued for about $30 \mathrm{~min}$. The resultant NPs suspension was centrifuged at $15000 \mathrm{rpm}$ for $15 \mathrm{~min}$ (Remi cold centrifuge). Supernatant was collected and used for determining the encapsulation efficiency.

\section{Encapsulation efficiency:}

CLM content in NPs were determined by a fully validated HPLC method ${ }^{[24-32]}$ after appropriate dilution with HPLC grade acetonitrile. About $20 \mu \mathrm{l}$ was injected into a HPLC system (Shimadzu LC-20AT) equipped with a UV detector (at $205 \mathrm{~nm}$ ) and Phenomenex Kinetex $5 \mu \mathrm{C} 18(250 \times 4.6 \mathrm{~mm}$ i.d., $5 \mu \mathrm{m}$ particle size) column. Optimised mobile phase, acetonitrile $(0.1 \mathrm{M})$ :potassium dihydrogen phosphate $(50: 50)$ was used, at flow rate of $1 \mathrm{ml} / \mathrm{min}$ and at a wave length of

\section{TABLE 1: COMPOSITION OF CHITOSAN NPS}

\begin{tabular}{lcc}
\hline Formulation & CS conc. & CS:STPP ratio \\
\hline F1 & & $1: 1$ \\
F2 & $0.1 \%$ & $1: 1.5$ \\
F3 & & $1: 2$ \\
F4 & & $1: 1$ \\
F5 & $0.2 \%$ & $1: 1.5$ \\
F6 & & $1: 2$ \\
F7 & & $1: 1$ \\
F8 & $0.5 \%$ & $1: 1.5$ \\
F9 & & $1: 2$ \\
\hline
\end{tabular}

CS is chitosan solution, STPP is sodium tripolyphosphate 
$205 \mathrm{~nm}$. Three samples from each formulation were injected into HPLC column with appropriate dilution. Entrapment efficiency (EE \%) in the CS-NPs were calculated according to the Eqn. ${ }^{[33,34]}, \% \mathrm{EE}=$ total amount of CLM loading-free CLM in the supernatant/ total amount of CLM loading $\times 100$.

\section{Size of NP, surface morphology and zeta potential:}

Mean particle size and zeta potential of prepared NPs were measured using a Malvern Nano ZS 90 (Malvern Instruments, UK) after appropriate dilution with double-distilled water. The mean particle size and distribution were measured based on photon correlation spectroscopy (dynamic light scattering) technique. The particle surface charge was quantified as zeta potential using Malvern Nano ZS 90 (Laser Doppler Electrophoresis).

\section{Scanning electron microscopy (SEM):}

The morphology of NPs was investigated using SEM (EM-LEO435VP, Carl Zeiss SMT Inc., NY).

\section{Differential scanning calorimetry (DSC):}

Thermograms of CLM, NP, physical mixture of CLM with polymer and NPs were carried out using DSC Shimadzu 60 with TDA trend line software to evaluate any possible interaction. The analysis was performed at a rate of $10.0^{\circ} / \mathrm{min}$ from $10^{\circ}$ to $300^{\circ}$

\section{Fourier-transform infrared spectroscopy (FTIR):}

FTIR of intact CLM, NPs and physical mixture were obtained from FTIR spectrophotometer, model Tensor 27, Bruker. Spectra were obtained by ATR technique. The scanning range was $4000-400 \mathrm{~cm}^{-1}$.

\section{In vitro drug release:}

In vitro release patterns were studied using conventional dialysis technique ${ }^{[35]}$. In this method CLM-loaded CS $\mathrm{NP}$ suspension (equivalent to $10 \mathrm{mg}$ ) was placed in a dialysis bag, which was immersed in a beaker containing $100 \mathrm{ml}$ phosphate buffer ( $\mathrm{pH}$ 7.4), continuous to acceptor fluid and dialyzed. Acceptor compartment was agitated continuously using a magnetic stirrer, sink the condition and the temperature was maintained at $37 \pm 1^{\circ}$. The drug which diffuses out of NPs into the continuous phase was periodically sampled and assayed using HPLC according to the method described for encapsulation efficiency. The mean calculated values were obtained from 3 replicates. In order to understand the kinetic and mechanism of drug release, the result of in vitro drug release study of NPs were fitted with various kinetic models ${ }^{[36,37]}$.

\section{Stability studies:}

The stability of different formulations was evaluated after the formulations were stored at room temperature and at $4^{\circ}$ in a freeze for a period of 6 mo. Samples were collected at every 1 mo interval and were viewed for sedimentation. Any changes in the particle size and zeta potential were assessed ${ }^{[38,39]}$.

\section{Antibacterial activity of the NP suspension:}

Minimum inhibitory concentration (MIC) of CLM NPs was determined by micro-dilution technique using S. pneumoniae. In vitro antibacterial assays were carried out adopting the Kirby Baurer method according to the National Committee for Clinical Laboratory Standards procedures for aerobic testing. Mueller-Hinton agar was used as growth media. To the sterile nutrient agar plates $100 \mu \mathrm{l}$ of the test organism was aseptically transferred and spread using a sterile L-shaped glass rod. The organism was allowed to settle on the medium for $5 \mathrm{~min}$ (seeding). Using a sterile cork borer, three bores of $6 \mathrm{~mm}$ were made and $100 \mu \mathrm{l}$ of the test sample (CLM, $1 \mathrm{mg} / \mathrm{ml}$ ) as a positive control and blank as negative control was transferred aseptically into the bore. The plates were incubated for $24 \mathrm{~h}$ at $37^{\circ}$. The tests were done in triplicates and the zones of inhibition were measured using standard HiMedia scale ${ }^{[40-42]}$.

\section{RESULTS AND DISCUSSION}

CLM-loaded CS NPs were prepared by ionic gelation method. Ionic gelation method was selected because of following interesting features: 1) NPs are formed spontaneously as a result of molecular linkage between negatively charged TPP phosphate ions and positively charged CS amino group. 2) NPs are obtained spontaneously under mild conditions without involving high temperature, organic solvent, and sonication. 3) Provides a continuous release of entrapped drug for prolonged time. CS mucoadhesive character increases residual time at the site of absorption. Initial trials were addressed in the selection of the optimal ratios for the formation of NPs of TPP and CS.

Encapsulation efficiency was in range of $12.1 \pm 0.67$ to $57.56 \pm 1.31 \%$. High encapsulation $(57.56 \pm 1.31 \%)$ of CLM in NPs indicated efficient loading of the drug, due to its low aqueous solubility. From these results, it was observed as the CS concentration increased from 0.1 to $0.2 \%$, encapsulation also increased at 
constant TPP concentration. But further increase in CS concentration led to a decrease in the encapsulation, which might be due to insufficient TPP to cross link. At a constant CS concentration, as the ratio of TPP increased, encapsulation increased due to more cross linking.

The results of particle size are reported in Table 2 . Mean particle size ranged from $155.31 \pm 23.26$ to $399.95 \pm 16.50 \mathrm{~nm}$. The mean particle size increased with increase in CS concentration. Lower the CS concentration, lower the viscosity, which resulted in better solubility and interaction between CS and TPP, and thus smaller particle size $(\mathrm{F} 1, \mathrm{~F} 2, \mathrm{~F} 3)^{[43]}$. Further increase in $\mathrm{CS}$ concentration resulted in increased particle size due to precipitation, this might be due to increase in the viscosity of the CS solution. Available TPP could not crosslink CS strongly, which led to increase in the particle size. In case of 0.2 and $0.5 \%$ CS concentration, as concentration of CS increased to $0.5 \%$, viscosity of solution increased, thus available TPP was not able to completely cross link, leading to increase in the particle size with decrease in encapsulation. At s constant CS concentration, increase in the TPP ratio resulted in increase in the particle size, but the yield decreased.

The value of polydispersity index (PDI) can range from 0.00 (mono-dispersed systems) to 1.00 (highlydispersed systems), where PDI value greater than 0.50 indicate a relatively broader size distribution ${ }^{[44]}$. However narrow size distribution was observed for all NPs and all NPs exhibited a relative mono-dispersed distribution except F1, F2 and F3.

From the results it was observed that as CS concentration increased, zeta potential also increased (F1, F4, F7). More the concentration of CS, more the unneutralised amine group on the surface of NPs, stronger the electrostatic repulsion between particles. Whereas increase in the TPP volume ratio decreased the zeta potential, due to more interaction was observed. This confirmed that the formation of NPs greatly depend on the concentration of free amine groups to cross link with TPP. Based on the above results, $0.2 \% \mathrm{CS}$ formulations were selected for further studies.

DSC thermogram of pure CLM showed a sharp endothermic peak at $221.81^{\circ}$ (fig. 1). The thermograms of formulation showed the same endothermic peak at similar temperature, this further confirmed that there was no drug to polymer interaction. The DSC thermogram of CLM, physical mixture and NPs are shown in fig. 1. Sharp endothermic peak at $223.01^{\circ}$ (fig 1a) corresponding to its melting temperature of CLM. However, no sharp endotherm was seen at $223.01^{\circ}$ in fig. $1 \mathrm{~b}$ and $\mathrm{c}$, which indicated that crystallinity of CLM has been reduced significantly in NPs. Hence, it could be concluded that the drug was present in the formulation in the amorphous phase and might have been homogeneously dispersed in the polymer matrix.

The FTIR spectra of CLM-loaded NPs, CLM and physical mixture ofCLM and polymer are shownin fig. 2 . CLM showed characteristic peaks of $\mathrm{OCH}_{3}$ stretching at $2880 \mathrm{~cm}^{-1}, \mathrm{CH}_{2}$ stretching at $2827 \mathrm{~cm}^{-1}, \mathrm{C}-\mathrm{CH}_{3}$ stretching at $2943 \mathrm{~cm}^{-1}, \mathrm{C}=\mathrm{O}$ stretching at $1727 \mathrm{~cm}^{-1}$, $\mathrm{C}-\mathrm{O}$ bending at $1366 \mathrm{~cm}^{-1}, \mathrm{C}-\mathrm{N}$ bending at $1171 \mathrm{~cm}^{-1}$. The spectra of both physical mixture and NPs did not show any prominent changes in the peak position in comparison to CLM spectra. These results revealed that there was no chemical interaction between CLM and CS.

The dissolution profile of intact CLM and selected CLM-loaded NPs are shown in fig. 3. In vitro drug release studies was carried out in phosphate buffer (pH 6.8) for 48 h. Release profile of CLM from NPs could be divided into two phases: initial burst release of around $10 \%$ at $1 \mathrm{~h}$ followed by slow release for $48 \mathrm{~h}$. As the TPP ratio increased, release decreased due to tight bonding. As the CS concentration increased, release decreased at constant TPP concentration. These

\section{TABLE 2: CHARACTERISTICS OF CLARITHROMYCIN-LOADED CHITOSAN NANOPARTICLES}

\begin{tabular}{lcccc}
\hline Formulation code & Encapsulation efficiency $(\%)$ & Mean particle size $(\mathrm{nm})$ & PDI & Zeta potential $(\mathrm{mV})$ \\
\hline F1 & $22.10 \pm 0.67$ & $155.31 \pm 23.26$ & $0.70 \pm 0.04$ & $+14.12 \pm 0.10$ \\
F2 & $38.71 \pm 3.44$ & $182.18 \pm 15.10$ & $0.76 \pm 0.20$ & $+13.81 \pm 0.03$ \\
F3 & $45.82 \pm 1.13$ & $208.14 \pm 16.50$ & $1.00 \pm 0.00$ & $+11.96 \pm 0.50$ \\
F4 & $67.41 \pm 2.61$ & $285.93 \pm 23.26$ & $0.19 \pm 0.03$ & $+26.83 \pm 0.40$ \\
F5 & $79.56 \pm 1.31$ & $297.87 \pm 15.10$ & $0.21 \pm 0.02$ & $+25.10 \pm 0.30$ \\
F6 & $45.15 \pm 4.05$ & $302.12 \pm 14.03$ & $0.19 \pm 0.02$ & $+23.97 \pm 0.23$ \\
F7 & $55.38 \pm 1.01$ & $332.90 \pm 13.95$ & $0.24 \pm 0.03$ & $+25.13 \pm 0.91$ \\
F8 & $41.99 \pm 1.40$ & $399.95 \pm 16.50$ & $0.35 \pm 0.02$ & $+22.20 \pm 0.91$ \\
F9 & $38.15 \pm 2.04$ & $360.05 \pm 26.06$ & $0.41 \pm 0.01$ & $+19.33 \pm 0.21$ \\
\hline
\end{tabular}


www.ijpsonline.com

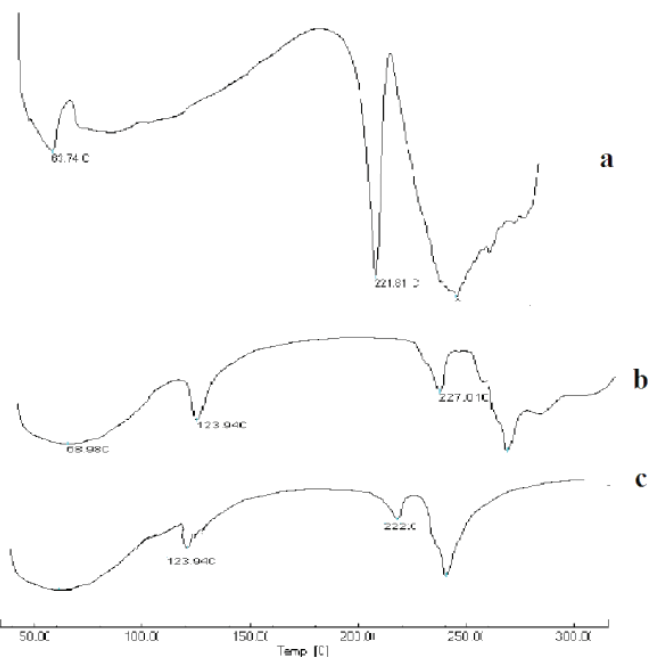

Fig. 1: DSC thermograms

(a) Clarithromycin, (b) physical mixture and (c) clarithromycinloaded NPs

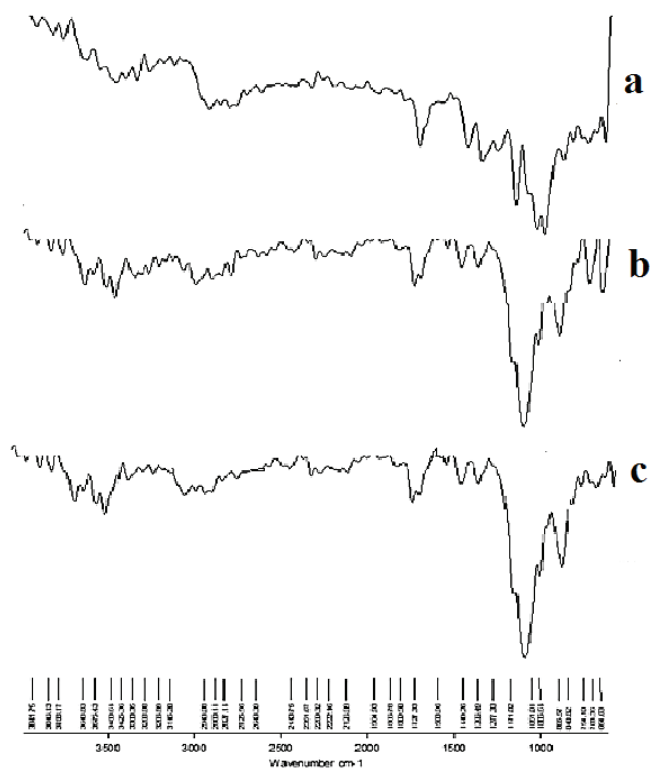

Fig. 2: FTIR spectra

(a) Clarithromycin, (b) physical mixture and (c) clarithromycinloaded NPs

result showed that initial release during first $2 \mathrm{~h}$ was $14,12,11$ and $8 \%$ for F4, F5, F6 and F7, respectively. The burst release of drug could be due to dissolution of the surface drug that is poorly entrapped in polymer matrix, slow release is due to diffusion of drug present in the core of CS NPs.

From the results it was evident that all the formulations were more linear towards Higuchi model with $\mathrm{R}^{2}$ value ranging from 0.843 to 0.964 indicating that drug release mechanism was by diffusion. In Korsemeyer-Peppas plot, the slope value for all formulations was found to be less 0.5 indicating Fickian diffusion. Kinetic data is mentioned in Table 3.
The SEM image of F4 (fig. 4) was found to be uniform and roughly spherical and sub spherical in shape, separated from each other, suggesting possible stabilisation of the NPs due to positive surface charges.

Results of 6 mo stability studies showed that there was no change in the appearance, particle size, zeta potential and PDI, stored at refrigerator condition (F4, F5, F6, F7, F8). While at room temperature, there was agglomeration of particles. Thus, refrigerator condition is suitable for storage of CS NPs.

The mean MICs of NPs are shown in fig. 5. The MIC of the CLM NPs was determined against a Gram-positive pathogens $S$. pneumoniae. The MIC values for the standard CLM solution was $32 \mu \mathrm{g} / \mathrm{ml}$ and for the CS

TABLE 3: KINETIC DATA OF SELECTED FORMUALTIONS

\begin{tabular}{lcccc}
\hline $\begin{array}{l}\text { Formulation } \\
\text { code }\end{array}$ & $\begin{array}{c}\text { Zero } \\
\text { Order }\end{array}$ & $\begin{array}{c}\text { First } \\
\text { order }\end{array}$ & Higuchi & $\begin{array}{c}\text { Korsemeyer- } \\
\text { Peppas }\end{array}$ \\
\cline { 2 - 5 } & $\mathbf{R}^{2}$ & $\mathbf{R}^{2}$ & $\mathbf{R}^{2}$ & $\mathbf{n}$ value \\
\hline F4 & 0.9095 & 0.8789 & 0.984 & 0.3050 \\
F5 & 0.8434 & 0.8539 & 0.9691 & 0.4574 \\
F6 & 0.9664 & 0.8854 & 0.9936 & 0.3512 \\
F7 & 0.9299 & 0.8667 & 0.9832 & 0.2142 \\
\hline
\end{tabular}

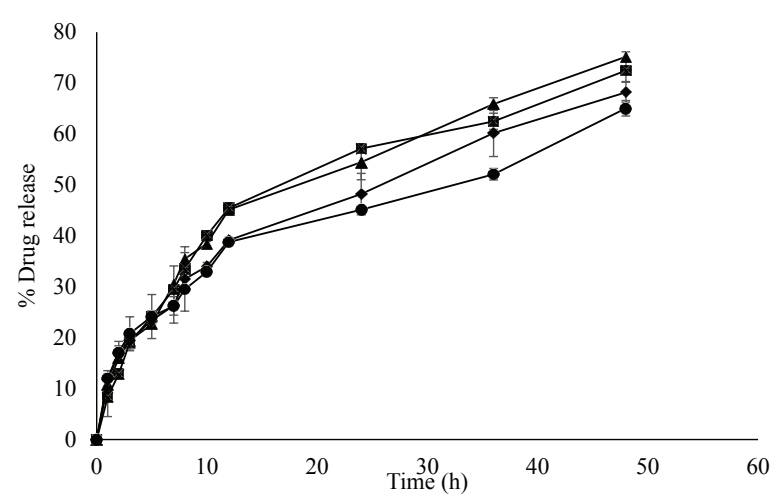

Fig. 3: In vitro dissolution profiles

In vitro dissolution profiles of clarithromycin-loaded chitosan

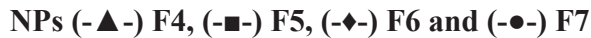

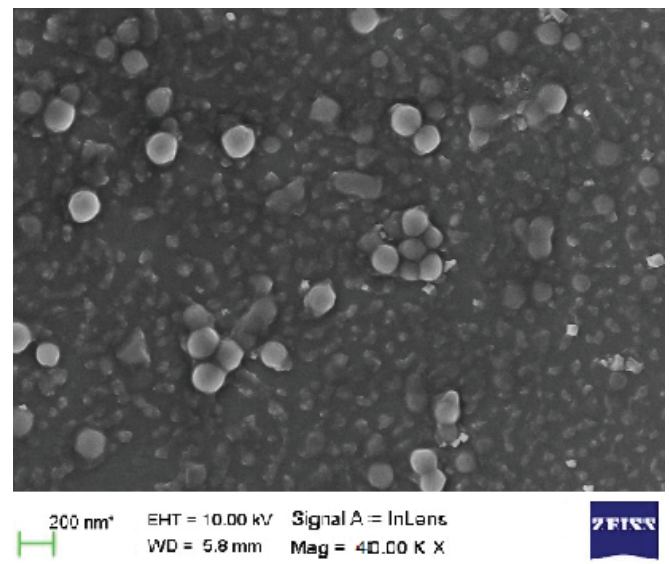

Fig. 4: SEM image of F4 formulation 


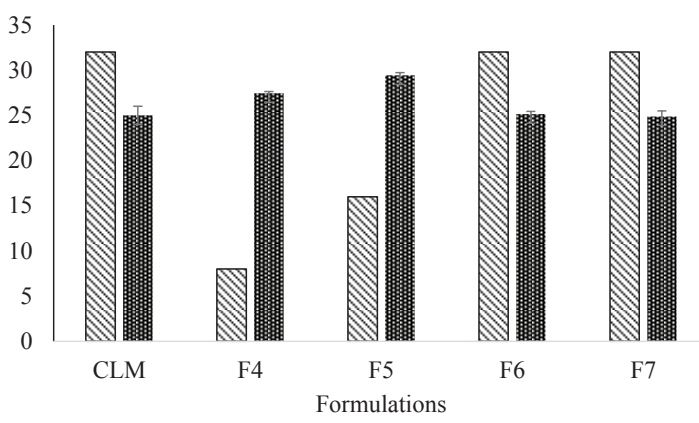

Fig. 5: MIC and zone of inhibition of clarithromycin and clarithromycin-loaded NPs

Bar diagrams represent minimum inhibitory concentration $(\mathrm{MIC} \mathbb{N}$ ) and zone of inhibition in $\mathrm{mm}$ (1) of clarithromycin (CLM) and clarithromycin-loaded NPs F4, F5, F6 and F7

formulations, F4, F5, F6 and F7, these were 8, 16, 32 and $32 \mu \mathrm{g} / \mathrm{ml}$, respectively. Based on these results, it was observed that particle size and release of drug from formulation had influenced the MIC. F4 formulation showed lower particle size and greater release of CLM when compared to other formulations, hence, the MIC of F4 is lower than that of other formulations. Due to stability issues remaining formulations were not further evaluated.

In vitro antibacterial activity of CLM NPs was determined by agar disc diffusion assay. Large and clear zones of inhibitions were observed around discs impregnated with CLM NPs, which clearly demonstrated the antibacterial effect of CLM NPs. The mean diameter of the inhibitory zones for F4 and F5 formulations was 27 and $29 \mathrm{~mm}$, respectively which were greater than those of the remaining formulation and CLM, as shown in fig. 5 .

This paper described the preparation of NPs using a hydrophilic polymer, which is non-toxic and biocompatible. The present study demonstrated that CS NPs prepared by ionic gelation method can be used to load CLM. NPs with efficient CLM loading were obtained, the concentration of CS strongly influenced the particle size. The results showed that these NPs could be suitable for treatment of respiratory tract infections caused by $S$. pneumoniae.

\section{Acknowledgements:}

The authors thank Calyx Chemicals and Pharmaceuticals Ltd., for providing CLM as gift sample for this work. Authors also thank to Dr. Divakar Goli, Principal, Acharya \& B M Reddy College of Pharmacy, Bangalore for providing required facilities to carry out this research work.

\section{Conflict of interest:}

The authors state that they have no conflicts of interest.

\section{REFERENCES}

1. Ahmed S, Ikram S. Chitosan based scaffolds and their applications in wound healing. Achiev Life Sci 2016;10:27-7.

2. Liu H, Du Y, Wang X, Sun L. Chitosan kills bacteria through cell membrane damage. Int J Food Microbiol 2004;95:147-55.

3. Vishu Kumar AB, Varadaraj MC, Gowda LR, Tharanathan $\mathrm{RN}$. Low molecular weight chitosans-preparation with the aid of pronase, characterization and their bactericidal activity towards Bacillus cereus and Escherichia coli. Biochem Biophys Acta 2007;1770(4):495-505.

4. Piras AM, Maisetta G, Sandreschi S, Esin S, Gazzarri M, Batoni G, et al. Preparation, physical-chemical and biological characterization of chitosan nanoparticles loaded with lysozyme. Int J Bio Macromol 2014;67:124-31.

5. Mintzer MA, Dane EL, O'Toole GA, Grinstaff MW. Exploiting dendrimer multivalency to combat emerging and re-emerging infectious diseases. Mol Pharm 2012;9:342-54.

6. Ning XH, Lee S, Wang ZR, Kim D, Stubblefield B, Gilbert E. Maltodextrin-based imaging probes detect bacteria in vivo with high sensitivity and specificity. Nat Mater 2011;10:602-7.

7. Viswanathan VK, Hodges K, Hecht G. Enteric infection meets intestinal function: how bacterial pathogens cause diarrhoea. Nat Rev Microbiol 2009;7(2):110-9.

8. Xiong $\mathrm{MH}$, Bao Y, Yang X, Zhu Y, Wang J. Delivery of antibiotics with polymeric particles. Adv Drug Del Reviews 2014;78:63-78.

9. Ray PC, Khan SA, Singh AK, Senapati D, Fan Z. Nanomaterials for targeted detection and photothermal killing of bacteria. Chem Soc Rev 2012;41:3193-209.

10. Andersson DI, Hughes D. Antibiotic resistance and its cost: is it possible to reverse resistance? Nat Rev Microbiol 2010;8(4):260-71.

11. Taubes G. The bacteria fight back. Science. 2008;312(5887):356-61.

12. Nigama A, Guptab D, Sharmac A. Treatment of infectious disease: Beyond antibiotics. Microbio Res 2014;169(910):643-51.

13. Rogueda PG, Traini D. The nanoscale in pulmonary delivery. Part 1: deposition, fate, toxicology and effects. Expert Opin Drug Deliv 2007;4:595-606.

14. Wacker M. Nanocarriers for intravenous injection-The long hard road to the market. Int J Pharm 2013;457(1):50-62.

15. Peters DH, Clissold SP. Clarithromycin: A review of its antimicrobial activity, pharmacokinetic properties and therapeutic potential. Drugs 1992;44(1):117-64.

16. Langtry HD, Brogden RN. Clarithromycin, A review of its efficacy in the treatment of respiratory tract infections in immunocompetent patients. Drugs 1997;53(6):973-1004.

17. Salem I, Duzgunes N. Efficacies of cyclodextrin-complexed and liposome encapsulated clarithromycin against Mycobacterium avium complex infection in human macrophages. Int J Pharm 2003:250(2):403-14.

18. Rodvold KA. Clinical pharmacokinetics of clarithromycin. Clin Pharmacokinet 1999;37(5):385-98.

19. Whitman MS, Tunkel AR. Azithromycin and clarithromycin: overview and comparison with erythromycin. Infect Control Hosp Epidemiol 1992;13(6):357-68. 
20. Partha S, Amit KG, Goutam R. Formulation and evaluation of chitosan-based ampicillin trihydrate nanoparticles. Trop J Pharm Res 2010;9:483-8.

21. Fazil M, Md S, Haque S, Kumar M, Baboota S, Sahni JK, et al. Development and evaluation of Rivastigmine loaded chitosan nanoparticles for brain targeting. Eur J Pharm Sci 2012;47(1):6-15.

22. Shanmuga SS, Rekha B, Sridhar S, Sangeetha D. Fabrication of chitosan/TPP nanoparticles as a carrier towards the treatment of cancer. Int J Drug Deliv 2013;5:35-42.

23. Calvo P, Remunan-Lopez C, Vila-Jato JL, Alonso MJ. Novel hydrophilic chitosan-polyethylene oxide nanoparticles as protein carriers. J Appl Polym Sci 1997;63:125-32.

24. Morakul B, Suksiriworapong J, Chomnawang MT, Langguth $\mathrm{P}$, Junyaprasert VB. Dissolution enhancement and in vitro performance of clarithromycin nanocrystals produced by precipitation-lyophilization-homogenization method. Eur J Pharm Biopharma 2014;88:886-96.

25. Saadat A, Zhu B, Haghi M, King G, Colombo G, Young PM, et al. The formulation, chemical and physical characterisation of clarithromycin-based macrolide solution pressurised metered dose inhaler. J Pharm Pharmacol 2014;66:639-45.

26. Sadana G, Surajpal V. RP-HPLC Method Development and validation for simultaneous estimation of clarithromycin and Paracetamol. ISRN Anal Chem 2013;2013:948547.

27. Shahbaziniaz M, Foroutan SM, Bolourchian N. Dissolution rate enhancement of clarithromycin using ternary ground mixtures: nanocrystal formation. Iran $\mathrm{J}$ Pharm Res 2013;12:587-98.

28. Zakeri-Milani P, Mousavian-Fathi N, Ghanbarzadeh S, Zarrintan MH, Valizadeh H. Application of lactobionic acid and nonionic surfactants as solubilizing agents for parenteral formulation of clarithromycin. Adv Pharm Bull 2012;2:37-42.

29. Chun WP, Xiaojian L, Frederick GV, Don H, Joseph BZ, Eun SP. Advanced spray dried design, physicochemical characterization, and aerosol dispersion performance of vancomycin and clarithromycin multifunctional controlled release particles for targeted respiratory delivery as dry powder inhalation aerosols. Int J Pharm 2013;455:374-92.

30. Venkateswaramurthy N, Sambathkumar R, Perumal P. Controlled release mucoadhesive microspheres of clarithromycin for the treatment of Helicobacter pylori infection. Der Pharm Lett 2012;4:993-1004.

31. Ozkan Y, Dikmen N, Işimer A, Günhan O, Aboul-Enein HY. Clarithromycin targeting to lung: Characterization, size distribution and in vivo evaluation of the human serum albumin microspheres. Farmaco 2000;55(4):303-7.

32. Amini H, Ahmadiani A. Sensitive determination of clarithromycin in human plasma by high-performance liquid chromatography with spectrophotometric detection. J Chromatogr B Analyt Technol Biomed Life Sci 2005:817:193-7.

33. Meng J, Sturgis TF, Youan BB. Engineering tenofovir loaded chitosan nanoparticles to maximize microbicide mucoadhesion. Eur J Pharm Sci 2011;44(1-2):57-67.

34. Wang X, Chi N, Tang X. Preparation of estradiol chitosan nanoparticles for improving nasal absorption and brain targeting. Eur J Pharm Biopharm 2008;70(3):735-40.

35. Harsha S, R C, Rani S. Ofloxacin targeting to lungs by way of microspheres. Int J Pharm 2009;380(1-2):127-32.

36. Shoaib MH, Tazeen J, Merchant HA, Yousuf RI. Evaluation of drug release kinetics from Ibuprofen matrix tablet using HPMC. Pak J Pharm Sci 2006;19(2):119-24.

37. Gautam S, Mahaveer S. In vitro drug release characterization models. Int J Pharm Res 2011;2(1):77-84.

38. Bency MM, Rangapriya, Rajendran. Evaluation and stability study of rifampicin loaded chitosan nanoparticles. World J Pharm Pharm Sci 2014;3(11).609-24.

39. Junise V, Saraswathi R. Development and characterization of inhaled chitosan nanoparticles loaded with Isoniazid. J Pharm Tech Res 2014;2(2):159-70.

40. NCCLS (2000) Methods for dilution antimicrobial susceptibility tests for bacteria that grow aerobically. Wayne, PA. National Committee for Clinical Laboratory Standards. Available from: https://clsi.org/media/1632/m07a10_sample. pdf.

41. Baurer AW, Kirby WM, Sherris JC, Turck M. Antibiotic Susceptibility testing by a standardized disk method. Am J Clin Path 1996;45:493-6.

42. Wani IA, Khatoon S, Ganguly A, Ahmed J, Ahmad T, Manzoor N. Structural characterization and antimicrobial properties of silver nanoparticles prepared by inverse microemulsion method. Colloids Surf B Biointerfaces 2013;101:243-50.

43. Fan W, Yan W, Xu Z, Ni H. Formation mechanism of monodisperse, low molecular weight chitosan nanoparticles by ionic gelation technique. Colloids Surf B Biointerfaces 2012;90:21-7.

44. Avadi MR, Sadeghi AM, Mohammadpour N, Abedin S, Atyabi F, Dinarvand R. Preparation and characterization of insulin nanoparticles using chitosan and arabic gum with ionic gelation method. Nanomedicine 2010;6(1):58-63. 